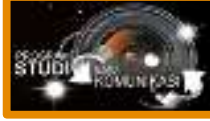

\title{
PENGARUH PENGGUNAAN FITUR SHOPEE GAMES TERHADAP CUSTOMER ENGAGEMENT PADA KALANGAN MAHASISWA DI KOTA MALANG
}

\author{
Priyo Dari Molyo ${ }^{1}$ | Irma Mufita ${ }^{1}$ | Fajar Zulhilmi ${ }^{1}$
}

${ }^{1}$ Program Studi IImu Komunikasi, Fakultas IImu Sosial dan IImu Politik, Universitas Merdeka Malang Jalan Terusan Raya Dieng 62-64 Malang, Jawa Timur 65115

\section{Correspondence \\ Irma Mufita}

Program Studi IImu Komunikasi, Fakultas IImu Sosial dan IImu Politik, Universitas Merdeka Malang, Jawa Timur 65115 Email: irma.mufita@unmer.ac.id https://doi.org/10.26905/nomosleca. v7i1.5541

\begin{abstract}
People to fulfill their needs by shopping online, in a middle of e-commerce providers offer same service. Shopee as one of the e-commerce comes with different things, namely the shoope games feature, which consumers can play interesting games and get prizes or rewards from their efforts to play these games. The purpose of this study was to determine the effect of Shopee Games features on Customer Engagement among students in Malang City. By using this type of quantitative research with a descriptive approach, the sampling technique used in this study was purposive sampling, the sample was taken as many as 35 respondents, and this study used simple regression as data analysis and also hypothesized. The results obtained by the author is the Shopee Games feature on Customer Engagement among Students in Malang City in $46,8 \%$.
\end{abstract}

Keywords: E-Commerce, Game Fitures, Customer Engagement

\begin{abstract}
Abstrak: Masyarakat berbelanja online di tengah puluhan e-commerce yang menawarkan jasa yang sama. Fitur shopee games adalah fitur yang di dalam nya konsumen dapat memainkan permainan yang menarik dan mendapatkan reward. Hal ini dimaksudkan agar terjadi customer engage sehingga muncul customer loyalty. Tujuan dari penelitian adalah untuk mengetahui pengaruh fitur terhadap customer engagement di kota Malang. Penelitian kuantitatif dengan pendekatan deskriptif, teknik sampling yang digunakan purposive sampling, sampel 35 responden, dan menggunakan regresi sederhana. Hasil penelitian yang didapatkan oleh adalah adanya pengaruh positif fitur Shopee games terhadap customer engagement di kalangan Mahasiswa di Kota Malang sebesar 46,8\%.
\end{abstract}

Kata Kunci: E-Commerce, Game Fitures, Costumer Engagement 


\section{1 | PENDAHULUAN}

Belanja secara online merupakan kebiasaan baru bagi masyarakat informasi. Kegiatan ini menjadi transakasi yang praktis dan disukai oleh banyak orang. Kelebihan dari berbelanja secara online adalah tidak perlu meninggalkan rumah, proses cepat, dan pilihan yang beragam (Harahap, 2018). Dalam praktiknya, kegiatan ini secara tidak langsung menjadi kebiasaan yang lumrah dari pada harus menghabiskan waktu menuju toko untuk memilih barang yang di inginkan. Proses komunikasi dilakukan dengan bertatap muka langsung sekarang mulai berganti dengan fitur chating yang mana penjual dan pembeli dapat menyepakati harga yang dipasang oleh penjual (Hermawan, 2017). Hal ini mengisyaratkan berbelanja sekarang semakin mudah dan tidak membutuhkan banyak waktu. Perkembangan teknologi menjadi pengaruh besar bagi perubahan kebiasaan masyarakt terutama dalam hal transaksi elektronik.

Semakin berkembangnya zaman membuat manusia semakin mudah atau praktis dalam melakukan aktivitas sehari-hari termasuk dalam berbelanja. Peran dari teknologi sangat sentral selain dapat mempermudah dalam berbelanja teknologi terbukti dapat menciptakan pasar digital yang cukup luas dan ramai digunakan, pasar tersebut kita kenal dengan e-commerce. Hal ini terlihat dari hasil kajian Sugiarti et al., (2020) jumlah transaksi dan jumlah produk y ang terjual di 5 online platform yaitu Tokopedia, Bukalapak, Shopee, Lazada dan Blibli mengalami peningkatan signifikan dari periode Juli-Desember 2019 ke Januari-Mei 2020. Dengan adanya e-commerce sangat memudahkan untuk memenuhi kebutuhan yang diinginkan, media baru menciptakan pasar digital dan membuat e-commerce bermunculan. Persaingan antar e-commerce dalam menyediakan wadah bagi para penjual untuk memasarkan dagangan mereka dengan membuatkan toko digital. Keunggulan lainnya untuk para pembeli yaitu dapat dengan mudah menemukan barang yang ingin dicari. Metodenya adalah dengan memasukan kata dari barang tersebut dalam search engine yang dimiliki dari setiap e-commerce, pembayaran dapat dilakukan melalui transfer bank atau melalui pihak ke 3. Kegiatan e-commerce meminimalisir komunikasi langsung. Hal ini dikarenakan komunikasi yang digunakan menggunakan perangkat teknologi untuk melakukan transaksi sehingga dinamakan transakasi elektronik. Dalam (Veza, 2019), menyebutkan kegiatan ecommerce memiliki keunggulan yang memudahkan konsumen. Kelebihannya adalah dapat menghemat waktu, dan konsumen dapat dengan mudah melakukan perbandingan harga. Aspek lain yang dirasa memudahkan adalah platform ecommerce dapat menjajikan penawaran berbagai barang dan jasa. Sehingga hal tersebut mengurangi kontak fisik antar pelanggan dan penjual. Fasilitas ini juga dikombinasikan dengan pembayaran yang cepat, pelacak order dan kecepatan 
pengiriman akan memenangkan hati konsumen.

Dari fenomena di atas terdapat konsep pertukaran sosial dapat diterapkan. Teori pertukaran sosial berasumsi bahwa manusia adalah mahkluk rasional. Yang artinya adalah terkadang manusia tidak ingin pengorbanan yang dilakukan tidak sesuai dengan apa yang didapatkan (Haliim, 2017; Maliki, 2018). Maka dari itu standard yang digunakan manusia untuk mengevaluasi pengorbanan dan penghargaan bervariasi. Ketika berinteraksi, mereka dituntut oleh tujuan (Wirawan, 2012). Hal ini sama dengan asumsi manusai adalah mahkluk yang rasional yang artinya adalah melihat cost dan reward, Mempertimbangkan untung dan rugi ini dianggap memotivasi dan memodifikasi tingkah laku manusia, dalam berhubungan sosial termasuk berbelanja secara online (Sugihartati, 2014). Merasa terfasilitasi dengan adanya e-commerce maka biaya yang dikeluarkan tidak terlalu banyak dengan reward yang hampir sama.

Dalam Sari (2020) perubahan perilaku digital di Indonesia tercatat perkembangan perusahaan e-commerce semakin banyak. Konsumen cenderung menyukai belanja online dikarenakan praktis, modern, dan dapat dilakukan setiap waktu tanpa harus susah mobilitas keluar rumah ketika menginginkan barang yang dibutuhkan. Fenemona dan pergeseran ini tentu menjadi peluang yang sangat bagus bagi perusahaan e-commerce untuk dapat menggaet konsumen dan menghasilkan keuntungan yang lebih besar.

Situs Databoks menulis, menurut lembaga riset asal Inggris Merchant Machine menyebutkan telah merilis daftar sepuluh negara dengan pertumbuhan e-commerce yang sangat pesat. Uniknya adalah Indonesia berada pada peringkat nomer satu dengan pertumbuhan e-commerce ialah 78\% pada 2018 di ikuti dengan Meksiko di peringkat ke dua yang nilai pertumbuhannya mencapai 59\% dan Filipina berada pada peringkat ke 4 dengan nilai pertumbuhan mencapai $51 \%$ pada 2018 . Hal ini dikarenakan jumlah pengguna internet di Indonesia yang lebih dari 100 juta pengguna menjadi alasan kekuatan perkemabangan e-commerce di Indonesia menjadi sangat pesat, dengan rata-rata uang yang dibelanjakan masyarakatnya di situs belanja atau e-commerce mencapai US \$ 228 per orang atau setara dengan Rp 3.19 juta per orang (Databook, 2019).

Hal ini mengakibatkan berjamurnya e-commerce yang ada di Indonesia. Kurang lebih ada 46 yang bersaing guna mengambil pasar belanja online di Indonesia, situs price grup telah merilis urutan marketplace yang merajai belanja online yang pertama adalah tokopedia, yang kedua shopee, dilanjutkan dengan bukalapak di urutan 3 besar yang merajai situs jual beli di Indonesia (Databook, 2019). Dari data tersebut dapat dilihat bahwa persaingan untuk mendapatkan pelanggan sangat luas, hal ini menunjukan perlu adanya strategi yang baru guna dapat menarik perhatian dan agar pelanggan betah untuk berbelanja pada satu toko saja. Maka 
dari itu tiga urutan e-commerce teratas tersebut selalu berinovasi guna menimbulkan rasa kesetian pelanggan agar terus menerus secara konsisten berbelanja dan ada sikap baik untuk merekomendasikan kepada orang lain.

Dari Databook (2019), shopee merupakan e-commerce yang berada pada urutan ke dua teratas pada daftar pengguna di Indonesia. Strategi yang di lakukan shopee dapat dibilang cukup unik yaitu dengan membuat fitur shopee games pada aplikasi yang mereka buat seperti halnya goyang shopee tujuan nya adalah agar pengguna marketplace bisa berlama-lama berada pada aplikasinya, goyang shopee adalah inovasi fitur shopee game pertama yang diluncurkan pada tahun 2018. Sejak di munculkan nya lebih dari 500 juta kali dimainkan oleh pengguna shopee sehingga pelanggan dapat betah berlama lama pada aplikasi tersebut dan secara tidak langsung pelanggan dapat merekomendasikan kepada teman lainya untuk ikut bermain shopee.

Shopee tangkap merupakan salah satu daftar permainan terbaru dalam fitur shopee games, shopee tangkap adalah permainan yang menggunakan fitur AR (augmented reality). Secara baik berhasil membawa fitur yang mudah dari sejumlah media sosial populer, menggabungkan dengan konsep e-commerce, dan meraciknya menjadi layanan jual beli yang unik, meski penjual dan pembeli tidak berkomunikasi transaksi tetap digawangi oleh shopee. Dalam peraturan yang dibuat oleh shopee para pengguna yang bermain fitur shopee games dan memenangkannya akan diumumkan oleh di halaman depan fitur shopee games dan mendapatkan notifikasi pada akun maksimal 14 hari setelah pengumuman di halaman shopee games.

Dalam konteks perkembangan e-commerce, teknologi diaplikasikan dalam berbagai bidang. Tidak terlepas dari kajian public relations, perkembangan teknologi komunikasi berpengaruh terhadap peranny. Peran public relations bisa berbentuk sebagai media public relation atau juga bisa menjadi kegiatan yang memiliki perspektif baru sehingga muncul pengertian Cyber PR. Saat ini praktisi public relation telah menggunakan internet sebagai salah satu strategi komunikasi, melalui internet inilah setiap individu bisa menjadi penerbit, konsumen atau melakukan kampanye untuk dapat memepengaruhi konsumen, dalam membuka perspektif baru (Gora , 2019).

Sebagai salah satu strategi dalam marketing public relation dalam Puspita (2019), alat-alat pemasaran hubungan masyarakat seperti publikasi, acara, sponsor, berita, pidato, kegiatan pelayanan masyarakat, dan media identitas. Sebagai salah satu implementasi marketing dalam public relation, e-commerce shopee menggunakan fitur games untuk berupaya membangun keterlibatan hubungan dengan konsumen. Dengan berinteraksi dengan konsumen maka terjalin hubungan komunikasi atau interaksi antara pemiliki kepentingan eksternal seperti 
konsumen dan pihak internal memelalui berbagai saluran yang dalam penelitian ini ialah saluran fitur games.

Irene (2019) pengaruh customer engagement melalui media sosial (jejaring sosial) terhadap kepercayaan merek sangat tinggi. Pada penelitian tersebut peneliti ingin mengetahui pengaruh terhadap customer (konsumen) yang dilakukan oleh sunsilk dalam media sosial (Facebook) tehadap kepercayaan merk. Dalam Hanifawati et al., (2019) pembentukan merk sangat efektif menggunakan promosi di media sosial. Sedangkan penelitian ini, ingin mengukur fitur shopee games dalam membangun customer engagement pada kalangan mahasiswa di Kota Malang yang menggunakan aplikasi shopee. Hal ini ditinjau dari sudut pandang sebagai pengguna.

\section{2 | METODE PENELITIAN}

Jenis penelitian yang digunakan dalam penelitian ini ialah dengan menggunakan metode kuantitatif yaitu penelitian yang berupa angka-angka dan analisis menggunakan statistik (Sugiyono, 2017). Metode kuantitatif digunakan untuk meneliti pada populasi atau sempel tertentu, pengumpulan data smenggunakan instrumen penelitian, analisis data bersifat kuantitatif statistik, dengan tujuan menguji hipotesis yang telah ditetapkan. Dalam hal ini yang menjadi responden adalah kalangan mahasiswa yang ada di Kota Malang. Metode penelitian kuantitatif adalah metode riset yang pola berfikirya secara deduktif. Demikian juga pola karakter teknik analisis terhadap data-data kuantitatif, dan riset ini memiliki hipotesis yang harus diuji dilapangan. Teknik sampling yang akan digunakan dalam penelitian ini adalah kuoata sampling. Sampling yang diambil dalam penelitian ini sebanyak 35 responden.

Pengujian validitas dimaksudkan untuk mengetahui keabsahan antara konsep dan kenyataan empiris, dapat diartikan uji validitas adalah suatu ukuruan yang menunjukan tingkatan ke validan suatu instrumen. Valid tidaknya suatu instrument dapat diketahui dengan membandingkan indeks Correlation Product Momenct Pearson dengan level signifikasi $5 \%(0,05)$ dan nilai $r$ (koefisien korelasi) lebih besar dari niai kritis yaitu 0,334 . Reliabilitas digunakan untuk menguji kebenaran hasil pengukuran suatu instrumen. Uji reliabilitas menunjukkan tingkat ketepatan suatu alat ukur atau uji yang digunakan untuk mengetahui sejauh mana pengukuran relatif konsisten apabila dilakukan pengukuran ulang. Teknik analisis data menggunakan regresi linier sederhana dan uji t. 


\section{3 | HASIL DAN PEMBAHASAN}

Analisis data diperlukan untuk menghitung besar nya pengaruh variabel bebas, yaitu fitur shopee games $(\mathrm{X})$ terhadap variabel terkait yaitu customer engagement pada kalangan mahasiswa di Kota Malang (Y). Konstanta sebesar 6,413, menunjukkan bahwa rata-rata pengaruh fitur shopee games terhadap customer engagement pada kalangan mahasiswa di Kota Malang memilki nilai skor 6,413. Koefisien regresi sebesar 0,764 artinya pengaruh fitur games terhadap customer engagement pada kalangan mahasiswa di Kota Malang akan meningkat 0,764 untuk setiap tambahan 1\% (Fitur Shopee Games). Jadi apabila fitur games mengalami peningkatan satuan maka customer engagement pada kalangan mahasiswa di Kota Malang akan meningkat sebesar 0,764. Koefisen tersebut bernilai positif, sehingga dapat dikatakan bahwa arah pengaruh variabel $\mathrm{X}$ terhadap customer engagement pada kalangan mahasiswa di Kota Malang adalah positif, dengan kata lain apabila fitur games meningkat maka akan diikuti peningkatan customer engagement pada kalangan mahasiswa di Kota Malang. Penjelasannya dapat dilihat pada table 1 .

Table 1. Regresi Linier

\begin{tabular}{c|c|c|c|c|c} 
Model & \multicolumn{2}{|c|}{$\begin{array}{c}\text { Unstandardized } \\
\text { Coefficients }\end{array}$} & $\begin{array}{c}\text { Standardized } \\
\text { Coefficients }\end{array}$ & T & Sig. \\
\cline { 1 - 3 } & B & Std. Error & Beta & & \\
(Constant) & 6,413 & 6,308 & & 1,017 &, 317 \\
Total (X) &, 764 &, 142 &, 684 & 5,392 &, 000
\end{tabular}

Sumber : Data diolah SPSS ver 23, 2020

Untuk mengetahui besar kontribusi variabel bebas fitur shopee games terhadap variabel terikat (customer engagement pada kalangan mahasiswa di Kota Malang) digunakan nilai R2, nilai R2 seperti dalam Tabel 2. Koefisien determinasi digunakan untuk menghitung besarnya pengaruh atau kontribusi variabel bebas terhadap variabel terikat. Dari analisis pada Tabel diperoleh hasil R2 (koefisien determinasi) sebesar 0,468 . Artinya bahwa $46,8 \%$ variabel customer engagement pada kalangan mahasiswa di Kota Malang akan dipengaruhi oleh variabel bebasnya, yaitu fitur shopee games. Sedangkan sisanya $43,2 \%$ variabel customer engagement pada kalangan mahasiswa di Kota Malang akan dipengaruhi oleh variabel-variabel yang lain yang tidak dibahas dalam penelitian ini. 
Tabel 2. Koefisien Korelasi dan Detreminasi

\begin{tabular}{|c|c|c|}
\hline $\mathrm{R}$ & R Square & Adjust R Square \\
\hline 0,684 & 0,468 & 0,452 \\
\hline
\end{tabular}

Sumber : Data diolah SPSS ver 23, 2020

Selain koefisien determinasi juga didapat koefisien korelasi yang menunjukkan besarnya hubungan antara variabel bebas yaitu fitur games dengan variabel customer engagement pada kalangan mahasiswa di Kota Malang, nilai R (koefisien korelasi) sebesar 0.684 , nilai korelasi ini menunjukkan bahwa pengaruh antara variabel fitur games dengan customer engagement pada kalangan mahasiswa di Kota Malang sebesar 46,8\%, artinya jika variabel bebas semakin ditingkatkan maka customer engagement pada kalangan mahasiswa juga akan mengalami peningkatan.

Hasil uji hipotesis bebas sebesar 46,8\%, artinya jika variabel bebas semakin ditingkatkan maka customer engagement pada kalangan mahasiswa juga akan mengalami peningkatan. atau nilai sig $\mathrm{t}(0,000)<\alpha=0.05$ maka model analisis regresi adalah signifikan. Hal ini berarti $\mathrm{H} 0$ ditolak dan $\mathrm{Ha}$ diterima sehingga dapat disimpulkan bahwa variabel terikat (customer engagement pada kalangan mahasiswa di Kota Malang) dapat dipengaruhi secara signifikan oleh variabel bebas fitur games. Dari hasil keseluruhan dapat disimpulkan bahwa variabel bebas mempunyai pengaruh yang signifikan terhadap customer engagement pada kalangan mahasiswa di Kota Malang. Dan dari sini dapat diketahui bahwa variabel bebas tersebut memberikan pengaruh yang kuat terhadap customer engagement pada kalangan mahaasiswa di Kota Malang.

Jual beli pada saat ini sangat lumrah dilakukan, apalagi di tunjang dengan teknologi yang semakin berkembang, hal ini dapat mempermudah aktifitas dan menunjang perekonomian pada masyarakat. Banyak sekali penyedia jasa $e-$ commerce yang sama sama menawarkan kemajuan bidang teknologi untuk bertransaksi jual beli salah satunya yang di gandrungi saat ini adalah aplikasi shopee. Proses perencanaan dan pengevaluasian program-program yang dapat merangsang kostumer untuk mengakses dan berbelanja di tengah persaingan $e$ commerce yang semakin kompetitif merupakan tugas marketing public relations. Shopee selaku e-commerce, di dalam persaingan dengan perusahaan-perusahaan lain harus mampu menyusun langkah-langkah maupun strategi promosi untuk menarik kostumer. Salah satunya ialah membuat fitur yang sedang ramai dimainkan saat ini yaitu fitur games.

Fitur games mampu mengikat para penggunanya khususnya pada kalangan 
mahasiswa. Dari segi (Confidence) Fitur shoppe sebagai platform penyedia atau ecommerce membuat para responden percaya kepada informasi atau games yang dibuat oleh shopee terbukti. Selanjutnya dari segi (Integrity) fitur shopee mampu membantu para responden untuk bisa mendapatkan kemudahaan dalam hal berbelanja termasuk gratis ongkir dan hadiah hadiah lainya. Berikutnya dari segi (Pride) fitur games mampu memunculkan perasaan positif konsumen, dari sebagian responden menyatakan, dan yang terakhir (Passion) fitur berhasil mengikat konsumen yang telah bermain. Dapat disimpulkan bahwa fitur games membantu responden dalam kegiatan berbelanja dan menimbulkan perasaan positif sehingga responden dapat terikat dan konsep dari hirarki customer engagement dapat terlaksana. Media yang digunakan dalam transaksi elektronik dapat menjadi media yang efektif untuk mempengaruhi sikap pelanggan. Seperti dalam kajian media panics ibu rumah tangga, dimana kelompok tertentu dapat terpengaruh dari penggunaan media sosial. Terutama bagi mereka yang memiliki intensitas tinggi maka akan membentuk sikap media panics atau kepanikan media atas informasi yang didapatnya (Muhammad \& Niki, 2018; Setiyaningsih, 2020).

Pada peneltian ini menggunakan teori pertukaran sosial dalam West (2008) teori pertukaran sosial didasarkan pada orang orang menpunyai pandangan ekonomis dalam hubungan mereka dengan orang lain dan mengenal prinsip harga atau cost dan mereka membandingkannya dengan keuntungan atau reward pada setiap hubungan mereka. Artinya semua orang menilai hubungan dengan, melihat pengorbanan (cost) dan penghargaan (reward). Pada penelitian ini konsumen di ajak untuk bermain adalah (cost) artinya konsumen mengorbankan waktunya tenaganya untuk memainkan games dengan harapan mendapatkan hadiah (reward) yang dapat digunakan oleh konsumen untuk membantunya berbelanja mendapatkan kepuasaannya. Dalam kaitanya teori dengan penelitian ini konsumen meluangkan waktunya dalam bermain games sehingga adanya keterikatan antara pelanggan dengan shopee yang saling menguntungkan satu dengan yang lain. Sehingga terdapat pengaruh postif fitur shopee games terhadap customer engagament.

Pada dasarnya inti dari penelitian ini adalah mengetahui seberapa kuat pengaruh pengaruh fitur games terhadap customer engagement pada kalangan mahasiswa. Dari hasil respon Mahasiswa di kota Malang, dapat diketahui bahwa program fitur games berpengaruh terhadap customer engagement pada kalangan mahasiswa. Proses yang mengawali terbentuknya engagement adalah adannya interaksi sehingga memunculkan sebuah reaksi, dari interaksi menuju reaksi melalui proses yang telah terlampaui. Hasil dari hipotesis penelitian ini adalah fitur games berpengaruh terhadap customer engagement pada kalangan mahasiswa. Keduanya memiliki arah positif, sehingga apabila fitur games pengaruhnya 
mengalami kenaikan maka menyebabkan meningkatnya customer engagement pada kalangan mahasiswa.

\section{4 | SIMPULAN}

Uji pengaruh fitur games terhadap customer engagement pada kalangan mahasiswa di Kota Malang menghasilkan hipotesis yang positif. Berdasarkan hasil penelitian dan pembahasan dapat ditarik kesimpulan bahwa terdapat pengaruh yang signifikan terhadap customer engagement. Fitur games berpengaruh positif terhadap customer engagement pada kalangan mahasiswa di Kota Malang. Dengan kata lain, apabila fitur shopee games meningkat maka diikuti peningkatan customer engagement sebesar 0,468. Artinya bahwa $46,8 \%$ variabel customer engagement pada kalangan mahasiswa dipengaruhi oleh fitur games.

\section{REFERENSI}

Data book. (2019). Pertumbuhan e-commers di Indonesia.

https://databoks.katadata.co.id/datapublish/2019/04/25/indonesia-jadi-negara-

dengan-pertumbuhan-e-commerce-tercepat-di-dunia

Databook. (2019). Pengunjung E-Commerce di Indonesia.

https://databoks.katadata.co.id/datapublish/2019/10/22/inilah-10-e-commercedengan-pengunjung-terbesar

Gora R. (2019). Riset Kualitatif Public Relations. Jakad Media Publishing. Jakad Media Publishing.

Haliim, W. (2017). Perspektif Pertukaran Sosial dalam Perilaku Politik Masyarakat pada Pilkada Kota Malang 2013. Politik Indonesia: Indonesian Political Science Review, 2(2), 201-226.

Hanifawati, T., Ritonga, U. S., \& Puspitasari, E. E. (2019). Popularitas Merek di Sosial Media: Analisis Pengaruh Waktu, Konten, dan Interaksi Merek. Esensi: Jurnal Bisnis Dan Manajemen, 9(1), 9-26.

Harahap, D. A. (2018). Perilaku belanja online di Indonesia: Studi kasus. JRMSIJurnal Riset Manajemen Sains Indonesia, 9(2), 193-213.

Hermawan, H. (2017). Sikap konsumen terhadap belanja online. WACANA: Jurnal Ilmiah IImu Komunikasi, 16(1), 136-147.

Irene, L. (2019). Analisa Pengaruh Content Marketing Terhadap Customer

Retention Dengan Brand Attitude dan Customer Engagement Sebagai Variabel

Perantara Pada Pengguna Rokok Wimsilak di Surabaya. Jurnal Strategi

Pemasaran, 6(2), 10.

Maliki, Z. (2018). Rekontruksi Teori Sosial Modern. UGM PRESS.

Muhammad, H. F., \& Niki, P. S. (2018). Pengembangan Human Resource 
Information System (HRIS) untuk Optimalisasi Manajemen Sumber Daya Manusia di Perguruan Tinggi. JUPITER (Jurnal Pendidikan Teknik Elektro), 3(2), $1-12$.

Puspita, I. M. (2019). Marketing Public Relation Peremajaan Merek sebagai Strategi Pemasaran dalam Membangun Citra Produk Baru. Warta Ikatan Sarjana Komunikasi Indonesia, 2(1), 19-26.

Sari, S. P. (2020). Strategi Meningkatkan Penjualan Di Era Digital. Scientific Journal Of Reflection: Economic, Accounting, Management and Business, 3(3), 291300.

Setiyaningsih, L. A. (2020). MEDIA PANICS IBU RUMAH TANGGA SETELAH MENGAKSES BERITA COVID-19 (2020). Jurnal Nomosleca, 6(2), 101-110. http://jurnal.unmer.ac.id/index.php/n/article/view/4721/2594

Sugiarti, Y., Sari, Y., \& Hadiyat, M. A. (2020). PERANAN E-COMMERCE UNTUK MENINGKATKAN DAYA SAING USAHA MIKRO KECIL DAN MENENGAH (UMKM) SAMBAL DI JAWA TIMUR. Kumawula: Jurnal Pengabdian Kepada Masyarakat, 3(2), 298-309.

Sugihartati, R. (2014). Perkembangan masyarakat informasi \& teori sosial kontemporer. Kencana.

Sugiyono. (2017). Metode Penelitian Kuantitatif, Kualitatif, dan R\&D. CV. Alfabeta. Veza, O. (2019). Perancangan E-commerce Untuk Memperluas Produk Komunikasi di PT. Golden Communication Berbasis Web Mobile. Jurnal Teknik Ibnu Sina (JT-IBSI), 4(1), 95-100.

West, T. (2008). Pengantar Teori Komunikasi Analisis dan Aplikasi. Salemba Humanika.

Wirawan, D. I. (2012). Teori-teori Sosial dalam Tiga Paradigma: fakta sosial, definisi sosial, dan perilaku sosial. Kencana 